\title{
Altered Expression and Function of Hepatic Transporters in a Rodent Model of Polycystic Kidney Disease
}

\author{
(1) Jacqueline Bezençon, (1)James J. Beaudoin, Katsuaki Ito, (1)Dong Fu, Sharin E. Roth, \\ William J. Brock, and (1) Kim L.R. Brouwer
}

Division of Pharmacotherapy and Experimental Therapeutics, UNC Eshelman School of Pharmacy, University of North Carolina, Chapel Hill, North Carolina (J.B., J.J.B., K.I., D.F., K.L.R.B.); DMPK Research Department, Teijin Pharma Limited, Hino, Tokyo, Japan (K.I.); Otsuka Pharmaceutical Development \& Commercialization, Inc., Rockville, Maryland (S.E.R.); and Brock Scientific Consulting, Montgomery Village, Maryland (W.J.B.)

Received February 26, 2019; accepted May 30, 2019

\section{ABSTRACT}

Autosomal dominant polycystic kidney disease (ADPKD) is a common form of inherited polycystic kidney disease (PKD) and is a leading cause of kidney failure. Fluid-filled cysts develop in the kidneys of patients with ADPKD, and cysts often form in their liver and other organs. Previous data have shown that bile acids are increased in the liver of polycystic kidney (PCK) rats, a rodent model of PKD; these changes may be associated with alterations in liver transporter expression and function. However, the impact of PKD on hepatic transporters has not been characterized. Therefore, this preclinical study was designed to investigate hepatic transporter expression and function in PCK compared with wild-type (WT) Sprague-Dawley rats. Transporter gene expression was measured by quantitative polymerase chain reaction, and protein levels were quantified by Western blot and liquid chromatography-tandem mass spectroscopy (LC-MS/MS)-based proteomic analysis in rat livers. Transporter function was assessed in isolated perfused livers (IPLs), and biliary and hepatic total glutathione content was measured. Protein expression of Mrp2 and Oatp1a4 was decreased 3.0-fold and 2.9-fold, respectively, in PCK rat livers based on Western blot analysis. Proteomic analysis confirmed a decrease in Mrp2 and a decrease in Oatp1a1 expression (PCK/WT ratios, $0.368 \pm 0.098$ and $0.563 \pm 0.038$, respectively; mean \pm S.D.). The biliary excretion of 5(6)-carboxy-2',7'-dichlorofluorescein, a substrate of Oatp1a1, Mrp2, and Mrp3, was decreased 28-fold in PCK compared with WT rat IPLs. Total glutathione was significantly reduced in the bile of PCK rats. Differences in hepatic transporter expression and function may contribute to altered disposition of Mrp2 and Oatp substrates in PKD.

\section{Introduction}

Polycystic kidney disease (PKD) is the fourth leading cause of kidney failure worldwide (Chebib and Torres, 2016). Autosomal dominant PKD (ADPKD) is caused by mutations in the polycystin-1 $(P K D 1)$ or polycystin-2 (PKD2) genes and is the most common form of PKD (prevalence of $>1$ in 1000 people). Autosomal recessive PKD

This work was supported, in part, by Otsuka Pharmaceutical Development \& Commercialization, Inc., and the National Institutes of Health National Institute of General Medical Sciences [Grants R01 GM041935 and R35 GM122576].

This work was presented, in part, at the 10th Biomedical Transporter Conference, the American Association of Pharmaceutical Scientists Transporter Workshop 2018, and the 2018 Drug Metabolism Gordon Research Conference. Any opinions, findings, conclusions, or recommendations expressed in this publication are those of the authors and do not necessarily reflect the views of the Otsuka Pharmaceutical Group or the National Institutes of Health

https://doi.org/10.1124/dmd.119.086785.
(ARPKD) is a rare neonatal form of PKD (Halvorson et al., 2010) and is caused by mutations in the polycystic kidney and hepatic disease 1 (PKHD1) gene (Harris and Torres, 2009; Hartung and Guay-Woodford, 2014). Despite the genetic differences between ADPKD and ARPKD, both diseases are associated with fluid-filled cysts and renal impairment. By the age of 70 years, $50 \%$ of patients with ADPKD require dialysis or kidney transplantation (Halvorson et al., 2010). Hepatic cysts are the most common extrarenal manifestation in patients with ADPKD and occur in $75 \%-90 \%$ of patients with ADPKD. Hepatic cysts typically develop later than renal cysts (Chauveau et al., 2000; Harris and Torres, 2009; Cnossen and Drenth, 2014), and their presence is generally considered benign, although hepatic biochemical abnormalities have been reported (Everson et al., 1988; Qian et al., 2003; Hogan et al., 2015). Increased concentrations of serum $\gamma$-glutamyl transferase or alkaline phosphatase of approximately two to five times the upper limit of normal have occurred in some patients with large polycystic livers (Chauveau et al., 2000; Qian et al., 2003).

ABBREVIATIONS: ADPKD, autosomal dominant polycystic kidney disease; ALT, alanine aminotransferase; ARPKD, autosomal recessive polycystic kidney disease; Bsep, bile salt export pump; CDCA, chenodeoxycholic acid; CDF, 5(6)-carboxy-2', $7^{\prime}$-dichlorofluorescein; CLuP, uptake clearance; CV, coefficient of variation; DCA, deoxycholic acid; Gapdh, glyceraldehyde 3-phosphate dehydrogenase; GSH, reduced glutathione; GSSG, glutathione disulfide; IPL, isolated perfused liver; $\mathrm{K}_{\mathrm{Bile}}$, biliary efflux rate constant; $\mathrm{K}_{\mathrm{BL}}$, basolateral efflux rate constant; $\mathrm{K}_{\mathrm{Lag}, \mathrm{Bile}}$, transit rate constant for biliary excretion; LC-MS/MS, liquid chromatography-tandem mass spectroscopy; LDH, lactate dehydrogenase; MDR/Mdr, multidrug resistance; MRP/Mrp, multidrug resistance-associated protein; NTCP/Ntcp, Na ${ }^{+}$-taurocholate cotransporting polypeptide; OATP/Oatp, organic anion transporting polypeptide; Ost, organic solute transporter; PCK, polycystic kidney; PKD, polycystic kidney disease; PKD1/2, Polycystic Kidney Disease 1/2; PKHD1, Polycystic Kidney and Hepatic Disease 1; SRM, selected reaction monitoring; WT, wild-type. 
TABLE 1

SRM parameters of peptides used for targeted analysis of hepatobiliary transporters (Oatp1a1, Oatp1a4, Oatp1b2, Ntcp, Mrp3, Mrp2, Bsep, Na ${ }^{+} /$ $\mathrm{K}^{+}$ATPase) for LC-MS/MS-based proteomic analysis in WT and PCK rat livers. The labeled amino acid residue of the internal standard is shown with an asterisk.

\begin{tabular}{|c|c|c|c|c|c|}
\hline \multirow{3}{*}{ Gene/Protein } & \multirow{3}{*}{ Probe Sequence } & \multicolumn{4}{|c|}{ SRM Transition } \\
\hline & & \multirow{2}{*}{ Parent Ion (Q1) } & \multicolumn{3}{|c|}{ Product Ions (Q3) } \\
\hline & & & 1 & 2 & 3 \\
\hline \multirow[t]{2}{*}{ Slcola1/Oatp1a1 } & EENLGITK & 452.2 & 645.4 & 531.4 & 418.3 \\
\hline & EENLGITK* & 456.2 & 653.4 & 539.4 & 426.3 \\
\hline \multirow[t]{2}{*}{ Slcola4/Oatp1a4 } & TFQFPGDIESSK & 678.4 & 832.4 & 735.4 & 563.4 \\
\hline & TFQFPGDIESSK* & 682.4 & 840.4 & 743.4 & 571.4 \\
\hline \multirow[t]{2}{*}{ Slcolb2/Oatp1b2 } & SVQPELK & 400.8 & 614.4 & 486.3 & 260.2 \\
\hline & SVQPELK* & 404.8 & 622.4 & 494.3 & 268.2 \\
\hline \multirow[t]{2}{*}{ Slc10al/Ntcp } & AAATEDATPAALEK & 679.9 & 729.4 & 915.5 & 628.4 \\
\hline & AAATEDATPAALEK* & 683.9 & 737.4 & 923.5 & 636.4 \\
\hline \multirow[t]{2}{*}{ Abcc3/Mrp3 } & FYVATSR & 422.4 & 696.4 & 533.3 & 434.2 \\
\hline & FYVATSR* $*$ & 427.4 & 706.4 & 543.3 & 444.2 \\
\hline \multirow[t]{2}{*}{$A b c c 2 / \mathrm{Mrp} 2$} & LTIIPQDPILFSGSLR & 885.5 & 989.6 & 1329.7 & 666.4 \\
\hline & LTIIPQDPILFSGSLR* & 890.5 & 999.6 & 1339.7 & 676.4 \\
\hline \multirow[t]{2}{*}{ Abcb11/Bsep } & STSIQLLER & 523.8 & 530.3 & 658.4 & 858.5 \\
\hline & STSIQLLER** & 528.8 & 540.3 & 668.4 & 868.5 \\
\hline \multirow[t]{2}{*}{$\mathrm{Na}^{+} / \mathrm{K}^{+}$ATPase $/ \mathrm{Na}^{+} / \mathrm{K}^{+}$ATPase } & AAVPDAVGK & 414.2 & 685.4 & 586.3 & 374.2 \\
\hline & AAVPDAVGK* & 418.2 & 693.4 & 594.3 & 382.2 \\
\hline
\end{tabular}

Although the impact of PKD on the hepatobiliary disposition of drugs has not been evaluated in humans, a case report in a patient with ADPKD who exhibited increased hepatic retention of the multidrug resistance-associated protein (MRP) 2 probe substrate ${ }^{99 \mathrm{~m}} \mathrm{Tc}$-mebrofenin suggests that MRP2 function may be impaired (Salam and Keeffe, 1989).

Until recently, ADPKD therapy has been directed only toward symptomatic treatment. Tolvaptan, an oral, selective vasopressin V2 receptor antagonist, has been shown to slow disease progression in patients with ADPKD, and was approved in April 2018 by the Food and Drug Administration to slow kidney function decline in adults at risk for rapidly progressing ADPKD (https://www.accessdata.fda.gov/ drugsatfda_docs/nda/2018/204441Orig1s000TOC.cfm). However, in two pivotal clinical trials (Torres et al., 2012, 2017), the incidence of alanine aminotransferase (ALT) elevations was $\sim 5 \%$ higher in patients receiving tolvaptan compared with placebo. Alternate causes for ALT elevations were ruled out, and, therefore, tolvaptan has been associated with liver injury in patients with ADPKD (Watkins et al., 2015). One possible explanation could be that tolvaptan interacts with hepatic transport proteins, especially bile acid transporters. In vitro studies indicated that tolvaptan is a substrate and competitive inhibitor of P-glycoprotein (MDR1/ABCB1) (Shoaf et al., 2011), whereas tolvaptan and the primary plasma metabolites DM-4103 and DM-4107 inhibit several hepatic transporters. For example, DM-4103 strongly inhibited the hepatic bile acid uptake transporter $\mathrm{Na}^{+}$-taurocholate cotransporting polypeptide (NTCP/SLC1OA1), the canalicular bile salt export pump (BSEP/ABCB11), and the basolateral efflux transporter MRP4/ABCC4 (Slizgi et al., 2016). Interestingly, elevated liver enzyme levels have not been reported in patients without ADPKD who were treated with tolvaptan (Watkins et al., 2015). Concomitantly, PKD may alter the function of hepatic transport proteins.

Polycystic kidney (PCK) rats have the same genetic defect as in ARPKD (i.e., PKHD1) and exhibit similar hepatorenal abnormalities (e.g., congenital hepatic fibrosis and development of cysts) as patients with ARPKD or ADPKD (Katsuyama et al., 2000; Lager et al., 2001, Masyuk et al., 2004). Various bile acids that are substrates for hepatic transporters (Dawson et al., 2009) are increased in PCK rat serum and liver (Ruh et al., 2013; Munoz-Garrido et al., 2015; Brock et al., 2018).
In addition, serum bilirubin concentrations are increased in PCK rats, suggesting impaired Mrp2 function (Mason et al., 2010; Shimomura et al., 2015). Furthermore, the biliary clearance of tolvaptan was significantly decreased in isolated perfused livers (IPLs) from PCK rats compared with wild-type (WT) rats (Beaudoin et al., 2019). The IPL is a physiologically relevant ex situ model (Brouwer and Thurman, 1996) that has been used to evaluate the hepatic transport and metabolic properties of various compounds (Chandra et al., 2005a; Miranda et al., 2008; Pfeifer et al., 2013).

This preclinical study was designed to elucidate possible mechanisms of altered hepatobiliary disposition of drugs and endogenous compounds in a rodent model of PKD. Hepatic transporter mRNA and protein expression were investigated in PCK and WT rat livers. Functional changes in organic anion transporting polypeptides (Oatps), Mrp2 and Mrp3 (Zamek-Gliszczynski et al., 2003) were measured in WT and PCK rat IPLs using 5(6)-carboxy-2',7'dichlorofluorescein (CDF), a fluorescent and metabolically stable probe substrate. In addition, hepatic and biliary total glutathione was quantified in WT and PCK rats.

\section{Materials and Methods}

Chemicals and Reagents. CDF was obtained from Sigma-Aldrich (St. Louis, $\mathrm{MO}$ ). All other chemicals and reagents were of analytical grade or higher and were readily available from commercial sources. The stable isotope-labeled peptides for $\mathrm{Na}^{+} / \mathrm{K}^{+}$ATPase $/ \mathrm{Na}^{+} / \mathrm{K}^{+}$ATPase, Slcola1/Oatp1a1, Slcola4/Oatp1a4, Slco1b2/Oatp1b2, Slc10a1/Ntcp, Abcc2/Mrp2, Abcc3/Mrp3, and Abcb11/Bsep (Table 1) were generated by a peptide synthesis platform (PEPscreen, Custom Peptide Libraries; Sigma-Genosys).

Animals. Male WT Sprague-Dawley or PCK (PCK/CrljCrl-Pkhd $\left.l^{\text {pck}} / \mathrm{Crl}\right)$ rats were purchased from Charles River Laboratories (Wilmington, MA). Rats were housed in a constant alternating 12-hour light/dark cycle, were allowed water and food ad libitum, and were acclimated for a minimum of 1 week prior to experimentation. All animal procedures complied with the guidelines of the Institutional Animal Care and Use Committee (University of North Carolina, Chapel Hill, NC). Single-pass IPL procedures were performed, and bile and liver tissue samples were collected at 16 weeks of age because the expected pathologic changes (e.g., hepatic cysts) in PCK rats are well defined at this age (Lager et al., 2001; Mason et al., 2010). 
Quantitative Reverse-Transcription Polymerase Chain Reaction Analysis. Total RNA from WT and PCK rat liver tissue samples were isolated using the RNeasy Plus Mini Kit (Qiagen GmbH, Hilden, Germany) according to the manufacturer instructions. The concentration and purity of isolated RNA were analyzed with a NanoDrop Spectrophotometer (ND-1000; Thermo Fisher Scientific, Waltham, MA). RNA was converted to cDNA, and cDNA was analyzed as described previously (Jackson et al., 2016). Briefly, reverse transcription was performed using a Life Technologies High Capacity cDNA Archive Kit, following the manufacturer instructions (Thermo Fisher Scientific, Carlsbad, CA). Abcc2 (Mrp2), Abcc3 (Mrp3), Abcb1b (Mdr1), Slcola1 (Oatp1a1), Slcola4 (Oatp1a4), Slcolb2 (Oatp1b2), Slc5la (Ost $\alpha)$, and Slc51b (Ost $\beta$ ) cDNA were analyzed from each sample in duplicate or triplicate using gene-specific TaqMan ${ }^{\circledR}$ assays [Abcc2 (catalog number Rn00563231_m1); Abcc3 (catalog number Rn01452854); Abcb1b (catalog number Rn01529252); Slcolal (catalog number Rn00755148); Slcola4 (catalog number Rn00756233); Slcolb2 (catalog number Rn01492635); Slc51a (catalog number Rn01763289_m1); and Slc51b (catalog number Rn01767005_m1); Thermo Fisher Scientific] and a Real-Time PCR System (Life Technologies QuantStudio 6 Flex; Thermo Fisher Scientific). The expression level of the studied genes was normalized against the selected reference gene glyceraldehyde 3-phosphate dehydrogenase (Gapdh; catalog number Rn01775763_g1; Thermo Fisher Scientific), and the relative quantification $\left(2^{-\Delta \Delta C t}\right.$, fold difference in PCK relative to WT) was calculated against the calibrator sample (cDNA from WT rat liver sample). No template (water) control was present on each PCR plate.

Western Blot Analysis. Membrane proteins from rat liver samples (from the median liver lobe) were extracted using a proteoExtract native membrane protein extraction kit (catalog number 444810; Calbiochem, San Diego, CA). The total protein was determined by a Pierce BCA Protein Assay Kit (Thermo Fisher Scientific) using the manufacturer protocol. Samples for Western blots were prepared according to the manufacturer instructions (Thermo Fisher Scientific); $35 \mu \mathrm{g}$ was loaded onto Bis-Tris $4 \%-12 \%$ (Oatp1a1, Oatp1a4, Oatp2b1, Ost $\beta$, Mdr1) or Tris Acetate 7\% (Mrp2, Mrp3) gels. After electrophoresis, the transfer of proteins to polyvinylidene fluoride membranes according to standard procedures was performed. Each protein was analyzed separately on a different membrane, and $\mathrm{Na}^{+} / \mathrm{K}^{+}$ATPase was probed on the same blot as the respective protein and used as the loading control. The membranes were incubated with antibody anti-Oatp1 (1:200; catalog number AB3670P; Millipore, Burlington, MA), anti-Oatp1a4 (1:500; catalog number AB3672P; Millipore), anti-Oatp1b2 (1:100; catalog number sc-376904; Santa Cruz Biotechnology, Dallas, TX), anti-Mrp3 (1:1000; catalog number 399095; Cell Signaling Technology, Danvers, MA), anti-Ost $\beta$ antibody (1:150; catalog number HPA008533; Sigma-Aldrich), anti-Mrp2 (1:20; catalog number MC-206; Kamiya Biochemical Company, Seattle, WA), anti-Mdr1b (1:100; catalog number sc-55510; Santa Cruz Biotechnology), or anti- $\mathrm{N}^{+} / \mathrm{K}^{+}$ATPase (1:5000; catalog number sc-28800; Santa Cruz Biotechnology) overnight in diluted $5 \%(\mathrm{w} / \mathrm{v})$ bovine serum albumin-Tris-buffered saline Tween 20. After washing, the blots were probed with horseradish peroxidase-conjugated anti-rabbit (for Oatp1a1, Oatp1a4, Ost $\beta$, and Mrp3; 1:7000; catalog number sc-2030; Santa Cruz Biotechnology) or horseradish peroxidase-conjugated anti-mouse IgG secondary antibody (for Oatp1b2, Mdr1, and $\mathrm{Na}^{+} / \mathrm{K}^{+}$ ATPase; 1:10,000; catalog number 115-035-003; Jackson ImmunoResearch, West Grove, PA) in 5\% milk for 1 hour at room temperature. Detection was enhanced using chemiluminescence reagents (ECLTM Select; GE Healthcare Bio-Sciences, Piscataway, NJ) and measured with ImageLab software version 4.1 (Bio-Rad, Hercules, CA). The data were normalized to loading control $\left(\mathrm{Na}^{+} / \mathrm{K}^{+}\right.$ATPase $)$using densitometric analysis to compare protein expression between WT and PCK rats with ImageJ version 1.51 (National Institutes of Health).

Protease Digestion and Solid Phase Extraction. As described previously (Malinen et al., 2019), membrane protein samples, as prepared for Western blot, were diluted to a concentration of $100 \mu \mathrm{g}$ membrane protein/100 $\mu \mathrm{l}$ and mixed in ammonium bicarbonate buffer $(25 \mathrm{mM})$ containing $5 \%$ deoxycholate and $10 \mathrm{mM}$ dithiothreitol. After incubation for $40 \mathrm{~min}$ at $56^{\circ} \mathrm{C}$, iodoacetamide was added (final concentration of $15 \mathrm{mM}$ ), and the sample was incubated for $30 \mathrm{~min}$ at room temperature. For protease digestion, samples were diluted 5-fold with ammonium bicarbonate buffer and digested using Lys-C protease (Thermo Fisher Scientific) in a protein/protease ratio of $20: 1$. After incubation for 4 hours at $37^{\circ} \mathrm{C}$, a protein/ trypsin ratio of $20: 1$ was applied followed by incubation overnight at $37^{\circ} \mathrm{C}$.
Formic acid was added (final concentration, $2 \% \mathrm{v} / \mathrm{v}$ ) to stop the protease reaction. The mixture of stable isotope-labeled peptides (Table 1) was used as internal standards. For solid-phase extraction, the cartridge (Oasis HLB; Waters Co., Milford, MA) was prewashed with methanol and equilibrated with $0.1 \%$ formic acid in water $(\mathrm{v} / \mathrm{v})$ before the sample was added. After washing the cartridge with $0.1 \%$ formic acid in water $(\mathrm{v} / \mathrm{v})$, the peptides were eluted by adding $0.1 \%$ formic acid in acetonitrile $(\mathrm{v} / \mathrm{v})$. A centrifugal evaporator (SpeedVac High-Capacity Concentrator; Thermo Fisher Scientific) was used to evaporate the eluate, and samples were reconstituted in $0.1 \%$ formic acid and $2 \%$ acetonitrile in water $(\mathrm{v} / \mathrm{v} / \mathrm{v})$. After centrifugation $(21,000 \mathrm{~g}, 1$ minute), the supernatant was analyzed by LC-MS/MS

Signature Peptide Selection and Quantification by LC-MS/MS. Signature peptides and internal standard peptides for each transporter (Li et al., 2008, 2009; Uchida et al., 2011; Prasad et al., 2014; Wang et al., 2015) (Table 1) were analyzed by LC-MS/MS [Thermo Scientific TSQ Quantum Ultra Triple Quadrupole Mass spectrometer (Thermo Fisher Scientific) with NanoAcquity UPLC (Waters Co.)] in the selected reaction monitoring (SRM) mode with three sets of transitions. As described previously (Malinen et al., 2019), samples were injected onto the Waters Acquity UPLC M-Class Symmetry C18 Trap Column (5, $180 \mu \mathrm{m} \times 20 \mathrm{~mm}$; Waters Co.) in $98 \%$ mobile phase A ( $0.1 \%$ formic acid in water) and $2 \%$ mobile phase $\mathrm{B}(0.1 \%$ formic acid in acetonitrile) (flow rate of $5 \mu \mathrm{l} /$ $\min$ for $3 \mathrm{~min}$ ). The peptides were first trapped and then separated on an analytical column (Waters Acquity UPLC HSS T3 NanoAcquity Column, 1.8, $100 \mu \mathrm{m} \times$ $100 \mathrm{~mm}$; Waters Co.) at a flow rate of $0.6 \mu \mathrm{l} / \mathrm{min}$, and a linear gradient of mobile phase B concentration of 5\% for $0-1$ minute, $5 \%-35 \%$ for $1-25 \mathrm{~min}$, and $35 \%-90 \%$ for $25-25.5 \mathrm{~min}$, followed by the washing step using $90 \%$ mobile phase B for $4.5 \mathrm{~min}$, and re-equilibrium for $10 \mathrm{~min}$. Xcalibur software (Thermo Fisher Scientific) was used to process the data by integrating the peak areas generated from the reconstructed ion chromatograms for the analyte peptides and their respective internal standards. Transporters were considered to be expressed when analyte peaks were detected in three sets of transitions. Then, the peak area ratios of the analyte peptide to its internal standard were calculated for three sets of transitions. To compare the expression levels of transporters among samples, the PCK/WT ratio was calculated with the peak area mean from each transition $(n=$ 3 ) and compared with $\mathrm{Na}^{+} / \mathrm{K}^{+}$ATPase PCK/WT ratio, assuming that there was no change in the $\mathrm{Na}^{+} / \mathrm{K}^{+}$ATPase protein in PCK compared with WT rat livers. The corresponding peptides, heavy labeled at $\left[{ }^{13} \mathrm{C}_{6}^{15} \mathrm{~N}_{2}\right]$-lysine $\left(\mathrm{K}^{*}\right)$ and $\left[{ }^{13} \mathrm{C}_{6}^{15} \mathrm{~N}_{4}\right]$-arginine $\left(\mathrm{R}^{*}\right)$ residues, were used as the internal standards.

Total Glutathione Determination. Total glutathione concentrations [reduced glutathione (GSH) plus glutathione disulfide (GSSG)] were determined according to the manufacturer instructions (CS0260; Sigma-Aldrich). Briefly, $10 \mu \mathrm{l}$ of blank bile (collected before IPLs) and 40-200 mg of liver tissue were diluted with $5 \%$ sulfosalicylic acid solution. The solutions were vigorously mixed by vortex and left for $10 \mathrm{~min}$ on ice prior to centrifugation $(10,000 \mathrm{~g})$ for $10 \mathrm{~min}$ at $4^{\circ} \mathrm{C}$. The supernatant volume was measured and samples were loaded on a 96-well plate and incubated for $5 \mathrm{~min}$ with the working solution containing $95 \mathrm{mM}$ potassium phosphate, $0.95 \mathrm{mM}$ EDTA, $0.031 \mathrm{mg} / \mathrm{ml} 5,5^{\prime}$ dithiobis(2-nitrobenzoic acid), $0.115 \mathrm{U} / \mathrm{ml}$ glutathione reductase from Baker's yeast, and $0.24 \%$ 5-sulfosalicylic acid. After adding NADPH to a final concentration of $0.038 \mathrm{mg} / \mathrm{ml}$ and mixing, the samples were read at $412 \mathrm{~nm}$ at 1-minute intervals for $5 \mathrm{~min}$ with a spectrophotometer (PowerWave XS; Biotek, Winooski, VT). Concentrations were calculated according to the manufacturer instructions.

CDF Disposition in Rat IPLs. WT and PCK rat livers were perfused as described previously (Brouwer and Thurman, 1996; Chandra et al., 2005a). Briefly, animals were anesthetized with ketamine/xylazine $(60: 12 \mathrm{mg} / \mathrm{kg}$, i.p.), and the bile duct and portal vein were cannulated. After cannulation and the collection of blank bile, the livers were perfused ex situ in a single-pass manner with continuously oxygenated Krebs-Henseleit buffer $(38 \mathrm{ml} / \mathrm{min})$. First, livers were perfused with blank perfusate for a 15-minute equilibration period, then with $\mathrm{CDF}(\sim 1 \mu \mathrm{M})$ for $30 \mathrm{~min}$ followed by perfusion for $20 \mathrm{~min}$ with CDF-free buffer. Outflow perfusate and bile were collected continuously. Outflow perfusate was collected for $50 \mathrm{~min}$ by sampling directly from the perfusate flowing out of the vena cava; bile was collected over 5 -minute intervals for $50 \mathrm{~min}$, and each sample was weighed to determine the total volume assuming a specific gravity of 1.0. Liver viability was monitored by gross morphology, portal perfusion pressure $\left(<15 \mathrm{~cm} \mathrm{H}_{2} \mathrm{O}\right.$ ), bile flow ( $>2 \mu \mathrm{l} / \mathrm{min}$ ) (Zhang et al., 2016), and by lactate dehydrogenase (LDH) levels in the outflow perfusate measured by the Pierce 


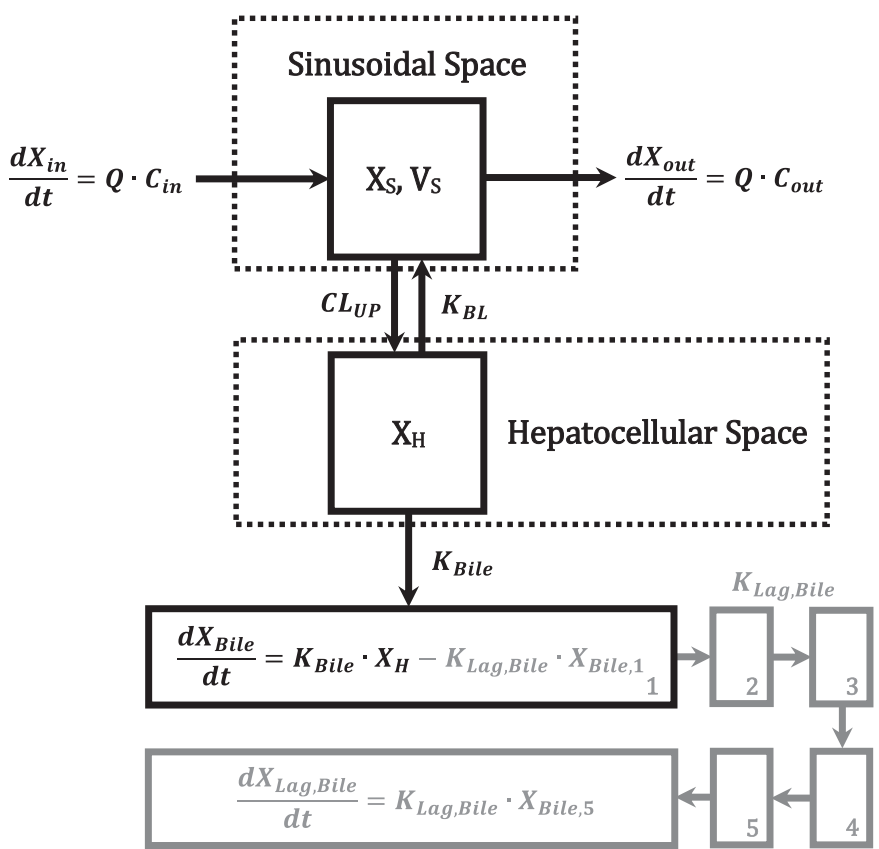

Fig. 1. Model scheme depicting the disposition of $\mathrm{CDF}$ in rat isolated perfused livers. The rate of change in the mass of CDF in the perfusate entering the sinusoidal compartment in relation to time, $d X_{i n} / d t$, was described by the product of the perfusate flow rate $(Q)$ and the inflow perfusate concentration $\left(C_{i n}\right)$. The product of $Q$ and the outflow perfusate concentration $\left(C_{\text {out }}\right)$ was used to describe the rate of change in the mass of CDF in the perfusate leaving the sinusoidal compartment in relation to time, $d X_{\text {out }} / d t$. The concentration in the sinusoidal compartment, $C_{S}$, was assumed to be equal to $C_{\text {out }}$. $C L_{U P}$ described the clearance of $\mathrm{CDF}$ from the sinusoidal to the hepatocellular space, while $K_{B L}$ and $K_{\text {Bile }}$ denoted the rate constants for the basolateral and biliary efflux from the hepatocellular space, respectively. The product of $K_{B i l e}$ and the hepatocellular amount of $\operatorname{CDF}\left(X_{H}\right)$ was used to describe the biliary excretion rate, $d X_{B i l e} / d t$.The incorporation of transit compartments $\left(X_{\text {Bile.1 } 1-5}\right)$ and a transit rate constant $\left(K_{\text {Lag.Bile }}\right)$ subsequent to the biliary excretion of CDF (highlighted by the gray shading) improved the model fit to the biliary excretion rate data for PCK rats. $X_{S}$ and $V_{S}$ represent the mass of CDF in, and the volume of, the sinusoidal space, respectively.

LDH Cytotoxicity Assay Kit (Thermo Fisher Scientific) per the manufacturer instructions.

CDF Sample Preparation. Perfusate and bile samples were thawed and diluted with buffer and analyzed for CDF by fluorescence spectroscopy using a Cytation 3 Imaging Reader (BioTek) at wavelengths of $485 \mathrm{~nm}$ (excitation) and $518 \mathrm{~nm}$ (emission). Two standard curves were prepared by diluting CDF in perfusate buffer, and blank bile was diluted in perfusate buffer (1:100). The lower limit of quantitation was $0.1 \mathrm{nM}$ for the perfusate buffer matrix and $10 \mathrm{nM}$ for the diluted blank bile matrix.

Pharmacokinetic Analysis. The hepatobiliary disposition of CDF was analyzed using a pharmacokinetic modeling approach. The compartmental model, consisting of a sinusoidal, a hepatocellular, and a bile compartment (scheme depicted in Fig. 1), was fit simultaneously to the average CDF outflow perfusate and biliary excretion rate data from rat IPLs. Data from WT and PCK rat IPLs were fit separately. A combined additive and multiplicative residual error model (Phoenix WinNonlin version 8.1; Certara USA, Inc., Princeton, $\mathrm{NJ})$ was used to estimate the parameters listed in Table 2. The bile compartment for PCK rat IPLs consisted of five transit compartments to describe the delay in the detection of CDF in bile. The differential equations, assuming linear conditions and an initial concentration of zero in all compartments, are as follows:

WT and PCK sinusoidal compartment:

$$
\frac{d X_{S}}{d t}=Q \cdot C_{i n}+K_{B L} \cdot X_{H}-\left(C L_{U P}+Q\right) \cdot C_{S}
$$

WT and PCK hepatocellular compartment:

$$
\frac{d X_{H}}{d t}=C L_{U P} \cdot C_{S}-\left(K_{B L}+K_{B i l e}\right) \cdot X_{H}
$$

WT and PCK concentration data in outflow perfusate expressed as $\frac{d X}{d t}$ :

$$
\frac{d X_{\text {out }}}{d t}=Q \cdot C_{S}
$$

WT concentration data in bile expressed as $\frac{d X}{d t}$ :

$$
\frac{d X_{\text {Bile }}}{d t}=K_{\text {Bile }} \cdot X_{H}
$$

PCK transit compartment 1 after biliary excretion:

$$
\frac{d X_{\text {Bile }, 1}}{d t}=K_{\text {Bile }} \cdot X_{H}-K_{\text {Lag, Bile }} \cdot X_{\text {Bile }, 1}
$$

PCK transit compartments $2-5$ after biliary excretion:

$$
\frac{d X_{\text {Bile }, n}}{d t}=K_{\text {Lag }, \text { Bile }} \cdot X_{\text {Bile }, n-1}-K_{\text {Lag, Bile }} \cdot X_{\text {Bile }, n}
$$

PCK concentration data in bile expressed as $\frac{d X}{d t}$ :

$$
\frac{d X_{\text {Lag, Bile }}}{d t}=K_{\text {Lag, Bile }} \cdot X_{\text {Bile }, 5}
$$

where $\frac{d X}{d t}$ represents the rate of change of CDF in a specific compartment with respect to time, and $X_{S}, X_{H}, X_{\text {out }}, X_{\text {Bile }}, X_{\text {Bile }, n}$, and $X_{\text {Lag, Bile }}$ represent the CDF mass in the sinusoidal space, hepatocellular space, outflow perfusate, bile (in the absence of delayed biliary transit), $n^{\text {th }}$ biliary transit compartment, and bile in the presence of delayed biliary transit, respectively. Other parameters are defined as follows:

$C_{i n}$ : inflow concentration.

$C L_{U P}$ : uptake clearance from the sinusoidal space to the hepatocellular space.

$K_{B L}$ : basolateral efflux rate constant from the hepatocellular space to the sinusoidal space.

$K_{\text {Bile }}$ :biliary efflux rate constant from the hepatocellular space to bile.

$K_{\text {Lag,Bile: }}$ transit rate constant for the biliary excretion of CDF.

$C_{S}$, calculated as $X_{S} / V_{S}$, represents the extracellular concentration in the

\begin{tabular}{|c|c|c|c|c|c|c|c|c|}
\hline \multirow{2}{*}{ Parameter } & \multicolumn{4}{|c|}{ WT } & \multicolumn{4}{|c|}{ PCK } \\
\hline & Estimate & $\mathrm{CV} \%$ & $2.5 \% \mathrm{CI}$ & $97.5 \% \mathrm{CI}$ & Estimate & CV\% & $2.5 \% \mathrm{CI}$ & $97.5 \% \mathrm{CI}$ \\
\hline$C L_{\mathrm{UP}}(\mathrm{ml} / \mathrm{min})$ & 8.80 & 10.9 & 6.74 & 10.9 & $4.69^{*}$ & 15.5 & 3.05 & 6.34 \\
\hline$K_{\mathrm{BL}}\left(\min ^{-1}\right)$ & 0.0828 & 13.5 & 0.0588 & 0.107 & $0.162 *$ & 10.3 & 0.125 & 0.200 \\
\hline$K_{\text {Lag,Bile }}\left(\min ^{-1}\right)$ & \multicolumn{4}{|c|}{ NA } & 0.136 & 23.8 & 0.0630 & 0.209 \\
\hline
\end{tabular}
sinusoidal compartment and was assumed to be equal to $C_{\text {out }}$. The sinusoidal space was assumed to be in equilibrium with the extracellular volume of the liver, $V_{S}$, and was estimated as $20 \%$ of the total liver mass (Watanabe et al., 2009; Hobbs

TABLE 2

Pharmacokinetic parameter estimates describing CDF disposition in single-pass IPLs from WT and PCK rats. Data represent mean \pm S.D. $(\mathrm{n}=3$ ). Statistically significant differences were based on nonoverlapping $95 \%$ CIs: $* \mathrm{P}<0.05$, WT vs PCK.

$\mathrm{NA}$, not applicable. $\mathrm{Cl}$, confidence interval. 


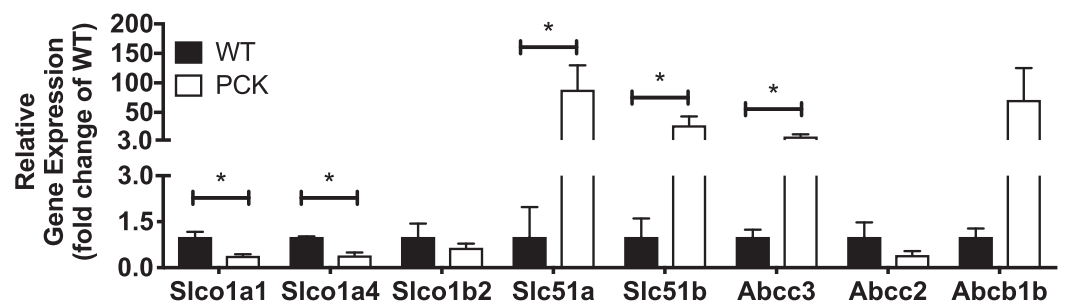

Fig. 2. Transporter gene expression in WT compared with PCK rat livers. Quantitation of mRNA isolated from liver tissue of WT and PCK rats. Data were normalized to Gapdh and are shown as the fold change from WT ( $2^{-\Delta \Delta \mathrm{Ct}}$ fold difference in PCK relative to WT) mean \pm S.D. $(n=3$ /group). Statistically significant differences were determined by an unpaired, two-tailed $t$ test $(* P<0.05$, WT vs PCK).

et al., 2012), which was converted to total liver volume $\left(V_{L}\right)$ using the average density of rat liver $(1.084 \mathrm{~g} / \mathrm{ml})$ (Pretlow and Pretlow, 1987). The observed outflow perfusate rate data were described by the perfusate flow rate multiplied by the concentration in the sinusoidal compartment $\left(Q \cdot C_{S}\right)$, whereas the observed biliary excretion rate data were described by $d X_{\text {Bile }} / d t$ and $d X_{\text {Lag,Bile }} / d t$ for WT and PCK rat IPLs, respectively.

Data Analysis. All data are presented as the mean and S.D. from $n=3$ livers per group (WT and PCK). Statistical tests [unpaired, two-tailed $t$ tests $(\alpha=0.05)$ corrected (only for proteomics data) by using the Bonferroni-Dunn multiplecomparison method] were performed using GraphPad Prism 7.0b for macOS (GraphPad Software, La Jolla, CA). Final parameter estimates were significantly different if the 95\% confidence intervals (CIs) between the WT and PCK groups did not overlap (Schenker and Gentleman, 2001).

\section{Results}

Transporter Gene Expression in WT Compared with PCK Rat Livers. The relative transporter gene expression in WT compared with PCK rat livers, assessed by quantitative polymerase chain reaction, is shown in Fig. 2. The mRNA levels of both Slcola1 (Oatp1a1) and Slcola4 (Oatp1a4) were significantly decreased in PCK rat livers by 2.6fold and 2.5-fold, respectively. Slc5 $1 a(\mathrm{Ost} \alpha), \operatorname{Slc51b}(\mathrm{Ost} \beta)$, and Abcc3 (Mrp3) mRNA levels were significantly increased by 88-fold, 28-fold, and 9-fold, respectively, in livers from PCK compared with WT rats. Abcc2 (Mrp2) and Slco1b2 (Oatp1b2) mRNA levels were decreased by 2.4-fold and 1.5-fold, and Abcb1b (Mdr1b) showed a 71-fold increase in PCK compared with WT rat livers, but differences were not statistically significant.

Transporter Protein Expression in WT Compared with PCK Rat Livers. Protein expression levels were determined using Western blot analysis (Fig. 3) and LC-MS/MS proteomic analysis (Fig. 4). Immunoblot analysis of liver tissue from WT and PCK rats revealed a significant decrease in Mrp2 and Oatp1a4 (3.0-fold and 2.9-fold, respectively) (Fig. 3) in PCK rat livers. A 1.4-fold, 2.0-fold, and 2.3 -fold increase in protein levels were detected in PCK rat livers for Mrp3, Ost $\beta$, and Mdr1b, respectively, but these differences were not statistically significant (Fig. 3). In addition, protein levels of Oatp1a1 and Oatp1b2 were decreased by 1.6-fold and 1.7-fold, respectively, in PCK rat livers, but differences were not significant (Fig. 3). Proteomics data showed a decrease in Oatp1a1, Ntcp, and Mrp2 with a PCK/WT ratio (mean \pm S.D.) of $0.563 \pm 0.038,0.691 \pm 0.097$, and $0.368 \pm 0.098$, respectively, but only Oatp1a1 and Mrp2 were significantly different (Fig. 4). Bsep protein expression was unchanged in PCK compared with WT rat livers (Fig. 4). Oatb1b2, Oatp1a4, and Mrp3 could not be detected with the selected sequence peptides (Table 1).

Total Glutathione (GSH + GSSG) Concentrations in Bile and Livers from WT and PCK Rats. Biliary total glutathione concentrations were reduced in PCK compared with WT rats (Fig. 5A). No significant changes in hepatic total glutathione concentrations were detected in PCK compared with WT rats (Fig. 5B).

Outflow Perfusate and Biliary Excretion Rates of CDF in Ex Situ IPLs from WT and PCK Rats. LDH release from IPLs into outflow perfusate was negligible $(<2 \%$ cytotoxicity; data not shown). To investigate whether changes in transporter expression in PCK rat livers affected substrate transport at a functional level, the hepatobiliary disposition of CDF was measured in ex situ IPLs. Although the body weight of WT and PCK rats was similar (458 \pm 34 and $495 \pm 3.6 \mathrm{~g}$, respectively), PCK rat livers $(28.1 \pm 9.1 \mathrm{~g})$ were approximately 2 -fold larger than WT rat livers $(15.4 \pm 1.0 \mathrm{~g})$. CDF outflow perfusate excretion rate versus time data were similar between WT and PCK rat IPLs, but the biliary excretion rates were markedly reduced in PCK IPLs (Fig. 6). The first four data points for the biliary excretion rates in PCK rats were below the limit of quantitation and are, therefore, not shown in Fig. 6.

Pharmacokinetic Modeling. The WT and PCK outflow perfusate and biliary excretion rate versus time data were well described by a model consisting of a single hepatocellular compartment (Figs. 1 and 6). A lag time for the movement of CDF from the hepatocellular space into bile was incorporated only in the model describing the PCK rat IPL data. The $\mathrm{CDF}_{\mathrm{Bile}}$ was significantly decreased in PCK IPLs by more than an order of magnitude (Table 2). The $\mathrm{CL}_{\mathrm{UP}}$ was significantly decreased ( $\sim 2$ fold $)$ and the $\mathrm{K}_{\mathrm{BL}}$ of $\mathrm{CDF}$ was significantly increased ( $\sim 2$ fold) in PCK IPLs.

\section{Discussion}

Previous studies suggest that the hepatobiliary disposition of endogenous and exogenous substrates may be altered in rodents with PKD. For example, various bile acids including unconjugated chenodeoxycholic acid (CDCA), deoxycholic acid (DCA), and lithocholic acid, and the glycine and taurine conjugates of CDCA and DCA are significantly increased in the serum and liver of PCK rats (Munoz-Garrido et al., 2015; Brock et al., 2018), a rodent model of PKD (Katsuyama et al., 2000; Masyuk et al., 2004). Although no significant increases in ALT, aspartate aminotransferase, or mRNA of the bile acid synthesis enzyme Cyp7a1 were detected in PCK rats (Munoz-Garrido et al., 2015), serum bilirubin concentrations were increased in PCK rats, which is suggestive of impaired Mrp2 function (Mason et al., 2010; Shimomura et al., 2015). Previous published data have shown that liver disease can affect hepatic transporter expression and function (Thakkar et al., 2017). The present study is the first to report altered protein expression and function of hepatic transporters in PCK rat livers.

The significant decrease in protein levels of Oatps in PCK rat livers was notable; Oatp1a4 measured by immunoblot and Oatp1a1 measured by immunoblot and LC-MS/MS were both decreased (Figs. 3 and 4). Decreased Oatp protein levels in PCK rat livers could have a significant impact on the hepatic disposition of Oatp substrates in this rodent model. The clinical implications of decreased hepatic OATP protein levels could lead to altered efficacy or toxicity of some drugs, particularly in patients with ADPKD. This warrants further investigation. Downregulation of $A b c c 2$ gene expression and a 3.0-fold decrease in Mrp2 protein levels were observed in PCK compared with WT rat livers (Figs. $2-4)$. In contrast, $A b c c 3$ gene expression was significantly increased in 


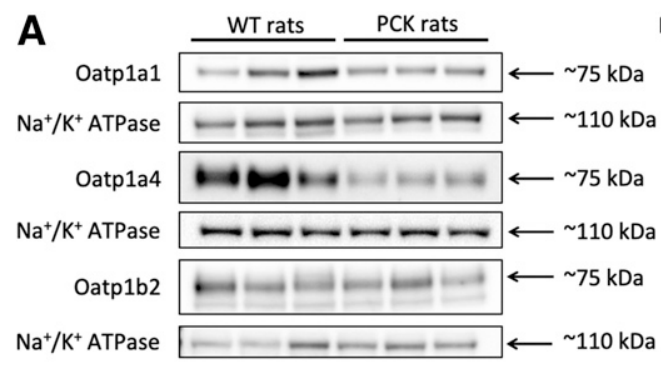

B

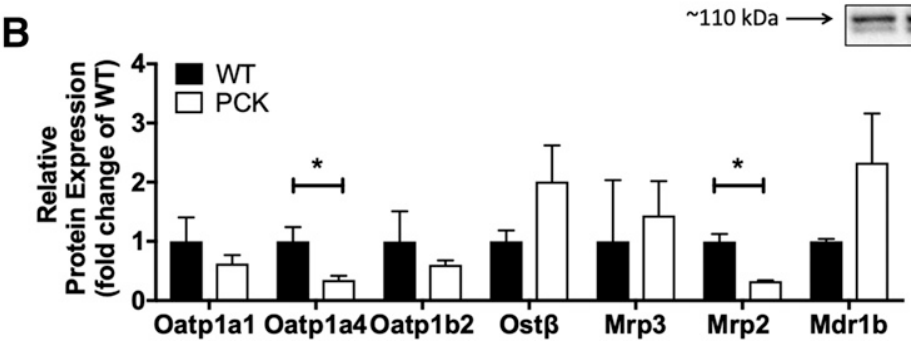

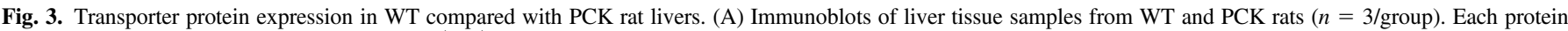

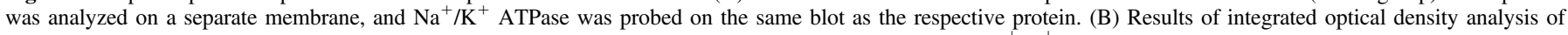

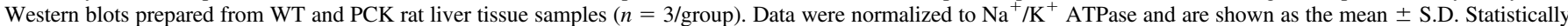
significant differences were determined by an unpaired, two-tailed $t$ test ( ${ }^{*} P<0.05$, WT vs PCK).

PCK rat livers. However, due to variability in protein levels, Mrp3 protein was not significantly different (Figs. 2 and 3).

Biliary concentrations of endogenous total glutathione $(\mathrm{GSH}+$ GSSG) were markedly reduced in PCK rats (Fig. 5A), consistent with decreased Mrp2 protein levels. Similar results were observed in Mrp2deficient $\mathrm{TR}^{-}$rats (Elferink et al., 1989). Interestingly, hepatic total glutathione concentrations were not significantly different in PCK compared with WT rats. Liver weights were greater in PCK rats, which might be due, in part, to the hepatic cysts that amount to $3.92 \mathrm{ml}$, on average, in 16-week-old PCK rats (Brock et al., 2018), or up to $15 \%$ of the liver tissue (Munoz-Garrido et al., 2015).

Altered hepatobiliary disposition of CDF in PCK IPLs clearly demonstrated that changes in protein expression translated to functional changes. $\mathrm{CDF}$ is a fluorescent anion that is excreted unchanged into bile by Mrp2 in rats (Zamek-Gliszczynski et al., 2003). CDF is also a substrate for Oatp1a1-mediated hepatic uptake and undergoes basolateral efflux by Mrp3 when Mrp2 function is impaired (Xiong et al., 2000; Zamek-Gliszczynski et al., 2003; Chandra et al., 2005b; Nezasa

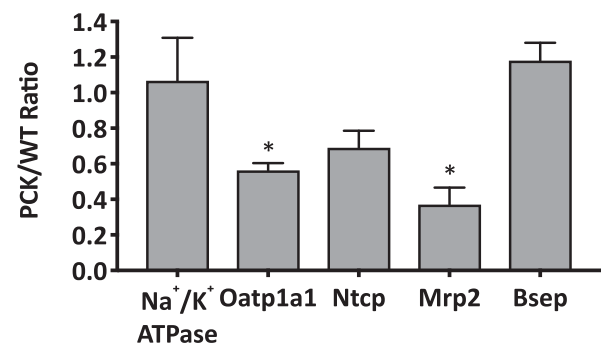

Fig. 4. LC-MS/MS-based proteomic analysis of transporter protein expression in WT compared with PCK rat livers. Bars represent the mean \pm S.D. of the PCK/WT ratio based on the average signal from three product ions (Table 1) $(n=3$ rats group). Statistically significant differences compared with the $\mathrm{Na}^{+} / \mathrm{K}^{+}$ATPase PCK/WT ratio were determined by an unpaired, two-tailed $t$ test corrected for multiple comparisons by using the Bonferroni-Dunn method $(* P<0.05)$. Transport proteins that were not detected by LC-MS/MS in the WT and PCK rat liver tissue samples are not shown in this figure. et al., 2006). The concentration of $\mathrm{CDF}(\sim 1 \mu \mathrm{M})$ used in the IPL studies was well below the reported $K_{\mathrm{m}}$ (Lineweaver-Burk constant) value (22 $\pm 10 \mu \mathrm{M}$ ) for uptake in rat hepatocytes (Zamek-Gliszczynski et al., 2003). A pharmacokinetic model assuming linear disposition was used to evaluate changes in the hepatic uptake, biliary excretion, and basolateral efflux of CDF. In general, the model adequately described the data with low coefficient of variation $(\mathrm{CV} \%)(<50 \%)$. Pharmacokinetic modeling revealed that the hepatic uptake clearance and biliary excretion rate constant of CDF were decreased by 1.9-fold and 28-fold, respectively, consistent with the observed decrease in Oatp1a1 and Mrp2 protein levels in PCK rat livers (Fig 3 and 4; Table 2). Interestingly, incorporation of a lag time for the movement of CDF from the liver to bile was required only in the PCK rat livers to adequately describe the data. One possible explanation for the lag time may be the dilated cystic bile ducts in PCK rats (Masyuk et al., 2004). In addition, the basolateral efflux rate constant of CDF, presumably mediated by Mrp3, was increased by 2-fold. Mrp3 serves as a compensatory route for the excretion of Mrp2 substrates when
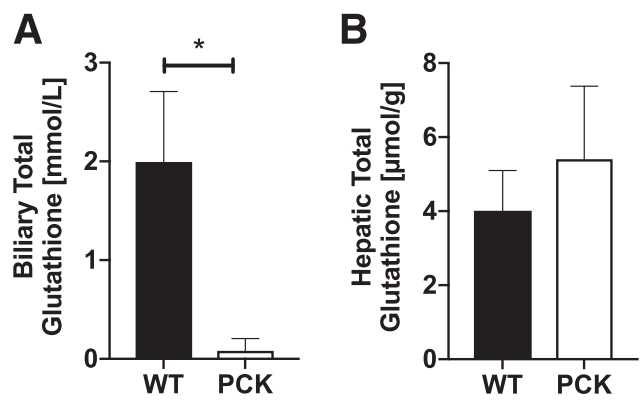

Fig. 5. Total glutathione (GSH + GSSG) concentrations in bile and liver of WT and PCK rats. Biliary total glutathione concentrations (millimoles per liter) (A) and hepatic total glutathione concentrations (micromoles per gram) (B) in WT (black bars) and PCK rats (white bars) ( $n=3$ /group). Data are shown as the mean \pm S.D. Statistically significant differences were determined by an unpaired, two-tailed $t$ test $\left({ }^{*} P<0.05\right.$, WT vs PCK). 


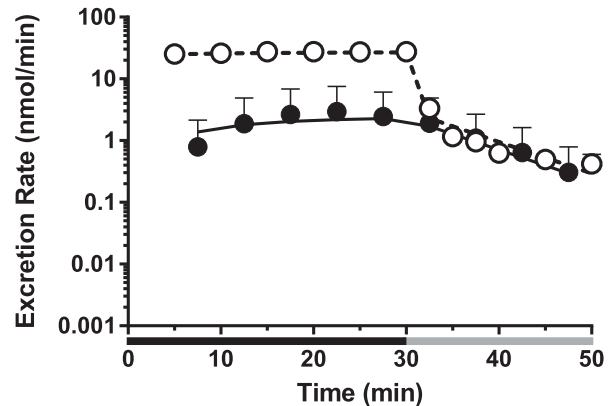

B Polycystic Kidney

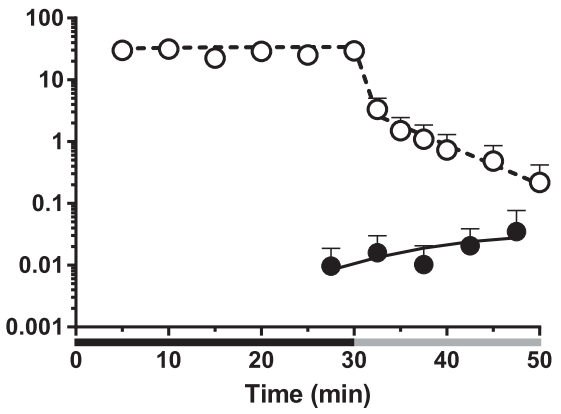

Fig. 6. Outflow perfusate and biliary excretion rates of CDF in ex situ IPLs from WT and PCK rats. Observed outflow perfusate excretion rate of CDF (open circles) and CDF biliary excretion rate (closed circles) in WT (A) and PCK (B) IPLs (mean \pm S.D.; $n=3$ /group). Livers were perfused with $\sim 1 \mu \mathrm{M}$ CDF-containing perfusate for $30 \mathrm{~min}$ followed by perfusion with CDFfree perfusate for an additional $20 \mathrm{~min}$, represented by the black and gray bars, respectively. The fit of the pharmacokinetic model, based on the scheme depicted in Fig. 1, to the biliary excretion (solid curves) and outflow perfusate (dashed curves) rate vs time profiles are plotted with the mean data. The first four data points for the biliary excretion of CDF in PCK IPLs were below the limit of quantitation and are not shown. biliary excretion is impaired ((König et al., 1999); Ogawa et al., 2000; Chandra and Brouwer, 2004).

These results reveal that protein levels and the function of hepatic drug transporters are altered in PCK rats. If similar alterations in hepatic transporters occur in humans with $\mathrm{PKD}$, these patients may be predisposed to liver injury by drugs that inhibit hepatic transporters, such as tolvaptan (Slizgi et al., 2016). Patients with ADPKD treated with tolvaptan have an increased risk of drug-induced liver injury and may have altered drug disposition compared with the population without ADPKD (Torres et al., 2012, 2017).

In conclusion, these novel findings indicate that significant alterations in hepatic transporter expression and function in PCK rat livers lead to decreased hepatic uptake and impaired biliary excretion of $\mathrm{CDF}$, a probe substrate of organic anion transporters. Impaired Oatp-mediated hepatic uptake and Mrp2-mediated biliary excretion of drugs and metabolites have important implications for the use of this rodent model in drug development investigations. Furthermore, altered hepatic transporter function can influence the hepatobiliary disposition of endogenous (e.g., bile acids) and exogenous compounds, and may be a predisposing risk factor in drug-induced liver injury.

\section{Acknowledgments}

The authors acknowledge Certara for providing academic research licenses for Phoenix software as part of the Center of Excellence program for educational institutions. Liver tissues from WT and PCK rats (16 weeks) were obtained from experiments conducted by Dr. Jason R. Slizgi. We acknowledge the support provided by the Biomarkers Mass Spectrometry sub-core supported in part by NIEHS grant P30ES010126 (J. Swenberg). We thank Dr. Noora Sjöstedt for her support with the visual abstract.

\section{Authorship Contributions}

Participated in research design: Bezençon, Beaudoin, Roth, Brock, and Brouwer.

Conducted experiments: Bezençon, Beaudoin, and Ito.

Performed data analysis: Bezençon, Beaudoin, Ito, Fu, Roth, Brock, and Brouwer.

Wrote or contributed to the writing of the manuscript: Bezençon, Beaudoin, and Brouwer.

\section{References}

Beaudoin JJ, Bezençon J, Cao Y, Mizuno K, Roth SE, Brock WJ, and Brouwer KLR (2019) Altered hepatobiliary disposition of tolvaptan and selected tolvaptan metabolites in a rodent model of polycystic kidney disease [published correction appears in Drug Metab Dispos (2019) 47:328]. Drug Metab Dispos 47:155-163.

Brock WJ, Beaudoin JJ, Slizgi JR, Su M, Jia W, Roth SE, and Brouwer KLR (2018) Bile acids as potential biomarkers to assess liver impairment in polycystic kidney disease. Int J Toxicol 37: $144-154$.

Brouwer KLR and Thurman RG (1996) Isolated perfused liver, in Models for Assessing Drug Absorption and Metabolism (Borchardt RT, Smith PL, and Wilson G eds) pp 161-192, Springer US, Boston.
Chandra P and Brouwer KLR (2004) The complexities of hepatic drug transport: current knowledge and emerging concepts. Pharm Res 21:719-735.

Chandra P, Johnson BM, Zhang P, Pollack GM, and Brouwer KLR (2005a) Modulation of hepatic canalicular or basolateral transport proteins alters hepatobiliary disposition of a model organic anion in the isolated perfused rat liver. Drug Metab Dispos 33:1238-1243.

Chandra P, Zhang P, and Brouwer KLR (2005b) Short-term regulation of multidrug resistanceassociated protein 3 in rat and human hepatocytes. Am J Physiol Gastrointest Liver Physiol 288: G1252-G1258.

Chauveau D, Fakhouri F, and Grünfeld JP (2000) Liver involvement in autosomal-dominant polycystic kidney disease: therapeutic dilemma. J Am Soc Nephrol 11:1767-1775.

Chebib FT and Torres VE (2016) Autosomal dominant polycystic kidney disease: core curriculum 2016. Am J Kidney Dis 67:792-810.

Cnossen WR and Drenth JP (2014) Polycystic liver disease: an overview of pathogenesis, clinica manifestations and management. Orphanet J Rare Dis 9:69.

Dawson PA, Lan T, and Rao A (2009) Bile acid transporters. J Lipid Res 50:2340-2357.

Elferink RP, Ottenhoff R, Liefting W, de Haan J, and Jansen PLM (1989) Hepatobiliary transport of glutathione and glutathione conjugate in rats with hereditary hyperbilirubinemia. $J$ Clin Invest 84:476-483.

Everson GT, Scherzinger A, Berger-Leff N, Reichen J, Lezotte D, Manco-Johnson M, and Gabow P (1988) Polycystic liver disease: quantitation of parenchymal and cyst volumes from computed tomography images and clinical correlates of hepatic cysts. Hepatology $\mathbf{8}$ : $1627-1634$

Halvorson CR, Bremmer MS, and Jacobs SC (2010) Polycystic kidney disease: inheritance, pathophysiology, prognosis, and treatment. Int J Nephrol Renovasc Dis 3:69-83.

Harris PC and Torres VE (2009) Polycystic kidney disease. Annu Rev Med 60:321-337.

Hartung EA and Guay-Woodford LM (2014) Autosomal recessive polycystic kidney disease: a hepatorenal fibrocystic disorder with pleiotropic effects. Pediatrics 134:e833-e845.

Hobbs M, Parker C, Birch H, and Kenworthy K (2012) Understanding the interplay of drug transporters involved in the disposition of rosuvastatin in the isolated perfused rat liver using a physiologically-based pharmacokinetic model. Xenobiotica 42:327-338.

Hogan MC, Abebe K, Torres VE, Chapman AB, Bae KT, Tao C, Sun H, Perrone RD, Steinman TI, Braun W, et al. (2015) Liver involvement in early autosomal-dominant polycystic kidney disease. Clin Gastroenterol Hepatol 13:155-164.6.

Jackson JP, Freeman K, and Brouwer KR (2016) Basolateral Efflux Transporters: a potentially important pathway for the prevention of cholestatic hepatotoxicity. Appl In Vitro Toxicol 2: 207-216.

Katsuyama M, Masuyama T, Komura I, Hibino T, and Takahashi H (2000) Characterization of a novel polycystic kidney rat model with accompanying polycystic liver. Exp Anim 49:51-55. König J, Rost D, Cui Y, and Keppler D (1999) Characterization of the human multidrug resistance protein isoform MRP3 localized to the basolateral hepatocyte membrane. Hepatology 29: $1156-1163$.

Lager DJ, Qian Q, Bengal RJ, Ishibashi M, and Torres VE (2001) The pck rat: a new model that resembles human autosomal dominant polycystic kidney and liver disease. Kidney Int 59: $126-136$.

Li N, Nemirovskiy OV, Zhang Y, Yuan H, Mo J, Ji C, Zhang B, Brayman TG, Lepsy C, Heath TG, et al. (2008) Absolute quantification of multidrug resistance-associated protein 2 (MRP2/ABCC2) using liquid chromatography tandem mass spectrometry. Anal Biochem 380:211-222.

Li N, Zhang Y, Hua F, and Lai Y (2009) Absolute difference of hepatobiliary transporter multidrug resistance-associated protein (MRP2/Mrp2) in liver tissues and isolated hepatocytes from rat, dog, monkey, and human. Drug Metab Dispos 37:66-73.

Malinen MM, Ito K, Kang HE, Honkakoski P, and Brouwer KLR (2019) Protein expression and function of organic anion transporters in short-term and long-term cultures of Huh7 human hepatoma cells. Eur J Pharm Sci 130:186-195.

Mason SB, Liang Y, Sinders RM, Miller CA, Eggleston-Gulyas T, Crisler-Roberts R, Harris PC, and Gattone VH II (2010) Disease stage characterization of hepatorenal fibrocystic pathology in the PCK rat model of ARPKD. Anat Rec (Hoboken) 293:1279-1288.

Masyuk TV, Huang BQ, Masyuk AI, Ritman EL, Torres VE, Wang X, Harris PC, and Larusso NF (2004) Biliary dysgenesis in the PCK rat, an orthologous model of autosomal recessive polycystic kidney disease. Am J Pathol 165:1719-1730.

Miranda SR, Lee JK, Brouwer KLR, Wen Z, Smith PC, and Hawke RL (2008) Hepatic metabolism and biliary excretion of silymarin flavonolignans in isolated perfused rat livers: role of multidrug resistance-associated protein 2 (Abcc2). Drug Metab Dispos 36:2219-2226.

Munoz-Garrido P, Marin JJ, Perugorria MJ, Urribarri AD, Erice O, Sáez E, Úriz M, Sarvide S, Portu A, Concepcion AR, et al. (2015) Ursodeoxycholic acid inhibits hepatic cystogenesis in experimental models of polycystic liver disease. J Hepatol 63:952-961.

Nezasa K, Tian X, Zamek-Gliszczynski MJ, Patel NJ, Raub TJ, and Brouwer KLR (2006) Altered hepatobiliary disposition of 5 (and 6)-carboxy-2', $7^{\prime}$-dichlorofluorescein in Abcg2 (Bcrp1) and Abcc2 (Mrp2) knockout mice. Drug Metab Dispos 34:718-723. 
Ogawa K, Suzuki H, Hirohashi T, Ishikawa T, Meier PJ, Hirose K, Akizawa T, Yoshioka M, and Sugiyama Y (2000) Characterization of inducible nature of MRP3 in rat liver. Am J Physiol Gastrointest Liver Physiol 278:G438-G446.

Pfeifer ND, Bridges AS, Ferslew BC, Hardwick RN, and Brouwer KLR (2013) Hepatic basolateral efflux contributes significantly to rosuvastatin disposition II: characterization of hepatic elimination by basolateral, biliary, and metabolic clearance pathways in rat isolated perfused liver. J Pharmacol Exp Ther 347:737-745.

Prasad B, Evers R, Gupta A, Hop CE, Salphati L, Shukla S, Ambudkar SV, and Unadkat JD (2014) Interindividual variability in hepatic organic anion-transporting polypeptides and P-glycoprotein $(\mathrm{ABCB} 1)$ protein expression: quantification by liquid chromatography tandem mass spectroscopy and influence of genotype, age, and sex. Drug Metab Dispos 42:78-88.

Pretlow TG II and Pretlow TP (1987) Cell Separation: Methods and Selected Applications pp 1-20, Academic Press, New York.

Qian Q, Li A, King BF, Kamath PS, Lager DJ, Huston J III, Shub C, Davila S, Somlo S, and Torre VE (2003) Clinical profile of autosomal dominant polycystic liver disease. Hepatology 37: $164-171$.

Ruh H, Salonikios T, Fuchser J, Schwartz M, Sticht C, Hochheim C, Wirnitzer B, Gretz N, and Hopf C (2013) MALDI imaging MS reveals candidate lipid markers of polycystic kidney disease. J Lipid Res 54:2785-2794.

Salam M and Keeffe EB (1989) Liver cysts associated with polycystic kidney disease: role of Tc-99m hepatobiliary imaging. Clin Nucl Med 14:803-807.

Schenker N and Gentleman JF (2001) On judging the significance of differences by examining overlap between confidence intervals. Am Stat 55:182-186.

Shimomura Y, Brock WJ, Ito Y, and Morishita K (2015) Age-related alterations in blood biochemical characterization of hepatorenal function in the PCK rat: a model of polycystic kidney disease. Int J Toxicol 34:479-490.

Shoaf SE, Ohzone Y, Ninomiya S, Furukawa M, Bricmont P, Kashiyama E, and Mallikaarjun S (2011) In vitro P-glycoprotein interactions and steady-state pharmacokinetic interactions between tolvaptan and digoxin in healthy subjects. J Clin Pharmacol 51:761-769.

Slizgi JR, Lu Y, Brouwer KR, St Claire RL, Freeman KM, Pan M, Brock WJ, and Brouwer KLR (2016) Inhibition of human hepatic bile acid transporters by tolvaptan and metabolites: contributing factors to drug-induced liver injury? Toxicol Sci 149:237-250.

Thakkar N, Slizgi JR, and Brouwer KLR (2017) Effect of liver disease on hepatic transporter expression and function. J Pharm Sci 106:2282-2294.
Torres VE, Chapman AB, Devuyst O, Gansevoort RT, Grantham JJ, Higashihara E, Perrone RD, Krasa HB, Ouyang J, and Czerwiec FS; TEMPO 3:4 Trial Investigators (2012) Tolvaptan in patients with autosomal dominant polycystic kidney disease. $N$ Engl J Med 367:2407-2418.

Torres VE, Chapman AB, Devuyst O, Gansevoort RT, Perrone RD, Koch G, Ouyang J, McQuade RD, Blais JD, Czerwiec FS, et al.; REPRISE Trial Investigators (2017) Tolvaptan in later-stage autosomal dominant polycystic kidney disease. N Engl J Med 377:1930-1942.

Uchida Y, Ohtsuki S, Katsukura Y, Ikeda C, Suzuki T, Kamiie J, and Terasaki T (2011) Quantitative targeted absolute proteomics of human blood-brain barrier transporters and receptors. J Neurochem 117:333-345.

Wang L, Prasad B, Salphati L, Chu X, Gupta A, Hop CE, Evers R, and Unadkat JD (2015) Interspecies variability in expression of hepatobiliary transporters across human, dog, monkey, and rat as determined by quantitative proteomics. Drug Metab Dispos 43:367-374.

Watanabe T, Kusuhara H, Maeda K, Shitara Y, and Sugiyama Y (2009) Physiologically based pharmacokinetic modeling to predict transporter-mediated clearance and distribution of pravastatin in humans. J Pharmacol Exp Ther 328:652-662.

Watkins PB, Lewis JH, Kaplowitz N, Alpers DH, Blais JD, Smotzer DM, Krasa H, Ouyang J, Torres VE, Czerwiec FS, et al. (2015) Clinical pattern of tolvaptan-associated liver injury in subjects with autosomal dominant polycystic kidney disease: analysis of clinical trials database. Drug Saf 38:1103-1113.

Xiong H, Turner KC, Ward ES, Jansen PL, and Brouwer KLR (2000) Altered hepatobiliary disposition of acetaminophen glucuronide in isolated perfused livers from multidrug resistanceassociated protein 2-deficient TR- rats. J Pharmacol Exp Ther 295:512-518.

Zamek-Gliszczynski MJ, Xiong H, Patel NJ, Turncliff RZ, Pollack GM, and Brouwer KLR (2003) Pharmacokinetics of 5 (and 6)-carboxy-2 $2^{\prime}, 7^{\prime}$-dichlorofluorescein and its diacetate promoiety in the liver. J Pharmacol Exp Ther 304:801-809.

Zhang A, Jia Y, Xu Q, Wang C, Liu Q, Meng Q, Peng J, Sun H, Sun P, Huo X, et al. (2016) Dioscin protects against ANIT-induced cholestasis via regulating Oatps, Mrp2 and Bsep expression in rats. Toxicol Appl Pharmacol 305:127-135.

Address correspondence to: Kim L.R. Brouwer, UNC Eshelman School of Pharmacy, The University of North Carolina at Chapel Hill, CB \#7569 Kerr Hall, Chapel Hill, NC 27599-7569. E-mail: kbrouwer@unc.edu 